\title{
Towards a Serious Game for Kurdish Language Learning
}

\author{
Aso Mohammad Darwesh \\ Dept. of Computer Science \\ University of Human Development \\ Sulaimani, Iraq \\ aso.darwesh@uhd.edu.iq
}

\author{
Mazen Ismaeel Ghareb \\ Dept. of Computer Science \\ University of Human Development \\ Sulaimani, Iraq \\ mezin.ismaeel@uhd.edu.iq
}

\author{
Shaahin Karimi \\ Dept. of Information Technology \\ University of Human \\ Development \\ Sulaimani, Iraq \\ shaahin.karimi@uhd.edu.iq
}

\begin{abstract}
Language learning is a set of techniques and methods used together to teach fundamentals of a language, including writing, reading, listening and comprehension. Usually begins by teaching letters. The purpose of this research was to initiate a scientific approach using serious games in order to discover a proper way to learn Kurdish language by writing approach. We studied related fields i.e. level of using technology with elementary school students, the method of teaching Kurdish language in the Kurdistan educational system and the students' enthusiasm for gaming. The outcome of the field-study shows there is a big gap between the current state and capacity of technology and serious game. Serious game is a composition of entertainment game with learning methods to help learning easy. We make the hypothesis that the game encourages pupils to learn rapidly. We aimed to prove a method that students start language learning by writing. In addition, there was no any serious game for learning Kurdish which it has two different alphabets and four main dialects. In this paper, we worked on Arami ${ }^{1}$ alphabets and south dialect (Sorani). We created an algorithm and a prototype to test our hypothesis. Our prototype is simple and easy to use, but at the same time it is dynamic that a teacher or parent can generate different game. A user might have a profile and result saves in a database. It helps supervisors to assess progress of learning and diagnosis of mistakes.
\end{abstract}

Keywords-serious game; tutor intelligent; Kurdish language, Arami alphabets

\section{INTRODUCTION}

A serious game is an act at first glance to have fun and distraction, but in reality, it pursuits certain goals and objectives which lay in behind of it, for example supporting or tutoring a new language.

On the other hand, gaming is seen as a playing for leisure, while computer games will create a new learning culture that matches students' interests and habits [1]. Generally games can provide a basic learning environment, this will grant engaging learning environment [2]. But we can say many people do not allow their children to play, at least during school period. In a survey we made in 20 primary schools in Sulaimani region, many pupils answered "no" to our first question in the survey (do you play any game?), in order to make the game more popular it is a good opportunity if the educational establishments and families let students play games to support learning. Due to the novelty of these approaches, there is no_attempt to adapt these aspects yet. The reason is that, there is no awareness among children about serious games and their difference with leisure games. However, there are some electronic games to learn Kurdish vocabularies in the field, but until now there has been no serious game for learning Kurdish language in any system. This term will define and publish in Kurdistan and Kurdish language must learn easily like all other languages.

Today's using of smart devices are very popular by Kurdish children. Unfortunately, most of them are used smart devices only for entertainment. We have gotten these primary results from the survey we took in 20 primary schools in Sulaimani which majority of teachers agreed on this curriculum.

\section{A. Our Motivations}

Nowadays immigration is an international issue and thousands of immigrant Kurdish family lives in exile. There is a strong desire among them to teach their mother language and culture to their kids. Type of life in $21^{\text {th }}$ century needs more sophisticated tools because of increasing immigration, and industries. Working mobility for some kind of personalities is a phenomenon. Who wants to travel with their families as they look for a system allowing their children learn easily. Where the new generation grew up in western countries and they learn country host languages and Latin alphabets easily, it's really hard for them to understand, read and write in Kurdish. However, there are some printed books, online websites and e-books are available to this goal, but it would be boring to children since the Aramaic alphabet is strange, hard to read to them.

The new generation is expert in using technology. We can say learning Kurdish by gaming would be one of the best methods of this group of people. It is interesting, available anytime and anywhere.

\footnotetext{
${ }^{1}$ Like Arabic alphabets (see table 1, column example)
} 
In other hand off-school context is an important aspect to teach concepts through serious games to children. Beside it, present educational systems have their own disadvantages like transport, i.e., traffic, get free for travelling [11], therefore education ministries might consider distance and eLearning system. From this point of view we can say that serious game at all provides a good opportunity for learning and it could be an alternative for present education in a special situation.

\section{B. Jojo}

Jojo is a serious game project developed by our group to address all issues mentioned above. This scientific project is a first attempt to make a very fantastic game for learning the Kurdish language (Arami alphabets). In this project, we have focused on the curriculum of the primary classes. Subjects are prepared and organized therefor children learns letters, words and sentences sequentially. The main goals behind our game are i) learn children aged from 4 to 12 (or foreign peoples) principles of Kurdish language, ii) will analyze user traces to classify them and make an adapted serious game in the future.

We named our game (Jojo) from Kurdish traditional game hide and seek. Our scenario is to challeng the player by hiding a value and encourages him/her to find it.

However, our prototype doesn't match full gaming requirements like environment, challenge and interaction, but it is proof of concept and it should be developed first version supporting different platforms.

The user begins playing by filling an anonymous form (User can start the game either by s/he account or anonymous) (Fig. 1); during the game an intelligent tutor accompanies the player 2to help him/her to find the correct solution. The help is either by providing a solved example, or by giving some hints. After each step, traces will be saved for sending to our server when the user is connected.

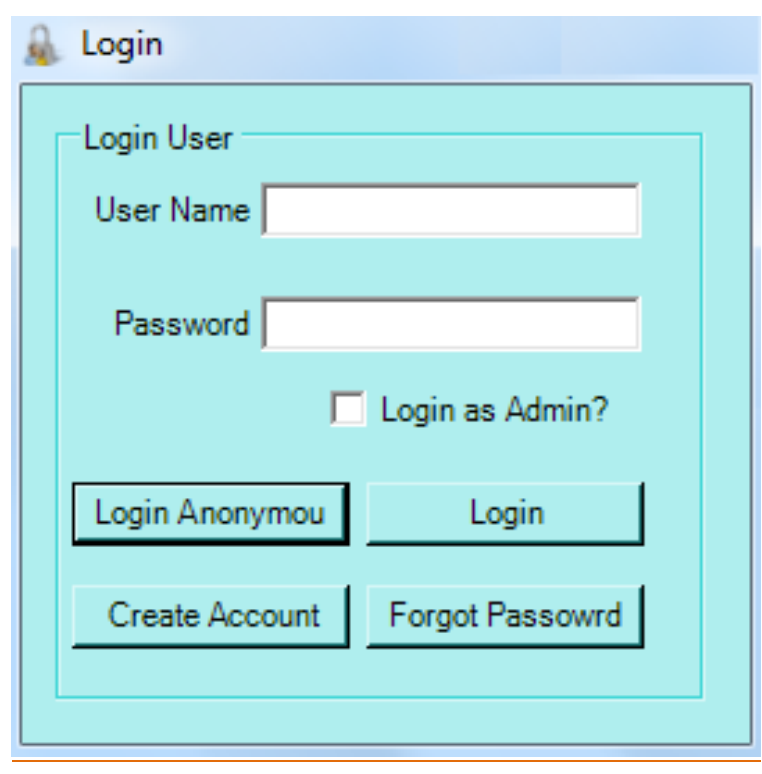

Fig. 1. Main interface of Jojo

The game structured on questions which are distributed in three parts (letters, words, sentences). Each part is also divided into different categories. The actual version works on the letters; (Table 1) shows type of words to learn letters.

Table 1: Word categories

\begin{tabular}{|c|c|c|c|}
\hline Code & $\begin{array}{l}\text { Types of } \\
\text { word }\end{array}$ & Explication & Example \\
\hline 1 & $\begin{array}{l}\text { Simple } \\
\text { word }\end{array}$ & $\begin{array}{l}\text { A simple word composed of at most } 4 \\
\text { non-accentuated letters }\end{array}$ & دار \\
\hline 2 & $\begin{array}{l}\text { Simple } \\
\text { Upper }\end{array}$ & $\begin{array}{l}\text { A composed word no more than } 4 \\
\text { letters, including } 1 \text { accentuated letter } \\
\text { (upper accent) }\end{array}$ & 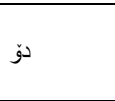 \\
\hline 3 & $\begin{array}{l}\text { Simple } \\
\text { Down }\end{array}$ & $\begin{array}{l}\text { A composed word no more than } 4 \\
\text { letters, including } 1 \text { accentuated letter } \\
\text { (down accent) }\end{array}$ & joر \\
\hline 4 & $\begin{array}{l}\text { Composed } \\
\text { Upper }\end{array}$ & $\begin{array}{l}\text { A word composed of at least } 3 \text { letters } \\
\text { including at least } 2 \text { accentuated letters } \\
\text { (upper accent) }\end{array}$ & ئنززنو \\
\hline 5 & $\begin{array}{l}\text { Composed } \\
\text { Down }\end{array}$ & $\begin{array}{l}\text { A word composed of at least } 3 \text { letters } \\
\text { including at least } 2 \text { accentuated letters } \\
\text { (down accent) }\end{array}$ & ردوريوه \\
\hline 6 & $\begin{array}{l}\text { Composed } \\
\text { Mixed }\end{array}$ & $\begin{array}{l}\text { A word composed of at least } 3 \text { letters } \\
\text { including at least } 2 \text { accentuated letters } \\
\text { (mixed accent) }\end{array}$ & رِيْو اس \\
\hline
\end{tabular}

This paper structured in several sections, section 1 is an introduction to our project named Jojo. Section 2, provides a state of art and related works. Section 3 is dedicated to primarily an analysis of our survey. In section 4 we described the implementation of Jojo Game. Section 5 describes our algorithm, how the game engine works. We concluded our paper by discussion about results and future works. 


\section{STATE OF ART}

\section{A. Taxonomy of serious games}

There are verity uses of serious games in public and private sectors, for instance, it has used in education and training [7]. This use of the game caused experience which varies between games and learning. There are a few censuses on game features to support learning. The result shows the learning achieves during engagement of the user. Therefore, they have developed some features of the game that might attract young learners [9]. These features are stated as below:

Rules and goals: setting up the game rules and goals, improve the performance because they show the player's performance and the target performance, which is activated greater attention and more motivations for the players to success.

Control: the contexts of the game are referring to control, which learners have ability to choose how to make decisions on different action that leads to the ending.

Mystery: information that has hidden from learner such as complexity, unexpected events and novelty this will bring to mind, curiosity for the player which is a key motivator to update existing knowledge with new one.

Fantasy: this is an imagination of a social or physical world but not really; this may enhance the motivation and learning of the users.

Challenge: it can describe as level of difficulty; the goal should be progressively more difficult, this will enhance learner motivation to reach maximum difficulty of the game.

On the other hand, during design a game we need to understand computer mediated flow. Flow is a complete activity or engage in activity and refers to the optimal activity [9]. For instance, when a person in psychological state involves with a goal driven activity, that lead to lose attention to other factors. It was considered flow antecedent, flow experience and flow consequences in designing an educational game [5]. The flow antecedent focuses on a clear goal, immediate feedback and potential control [5]. The flow of experience refers to control over the activity through awareness and concentrations. This is lead to increase learning, exploratory behavior and positive effect [6]. (Fig 2) below shows the flows of computer mediated environments.

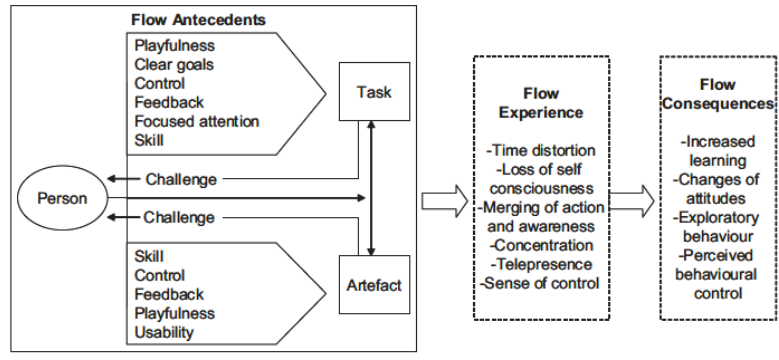

Fig. 2. Flow in computer-mediated environments [5]

\section{B. History of serious games}

Serious game implies a specific type of activity in education and learning. The main aim of it lays on achieving predefined objectives through goal-based game. As Michael \& Chen stated in [15] "games that do not have entertainment, enjoyment or fun as their primary purpose".

However, serious games look like a new phenomenon, but its market worth reaches 1.5 billion $€$ in 2010 [16].

Serious games have a long term history. As mentioned in [12] this topic relays to the Renaissance, which for the first time appears in literature. Later on a Swedish novel deals with this subject too in a book titled "The serious game". There are another similarity appears in the literature like Mike Harfield in his autobiography as a Cricket player. [18]. The paper lists many examples that serious game used for teaching purposes. This meant using of serious games in daily activities to learn has a long history.

Later, they classify serious game in the new generation, e.g. video games and first digital games such as chess games. History of serious games indicates that the United Kingdom is birthplace of serious games [17].

Serious games in video versions used for preparing human against unpredictable events like a nuclear explosion.

Ancestors of the current serious games can be categorized in 6 main sub list: Education The Oregon Trail (MECC, 1971), Healthcare Captain Novolin (Raya Systems, 1992), Defense Military Battlezone or Army Battlezone, customized version of Battlezone (Atari, 1980), Art \& Culture Versailles 1685 (Cryo, 1997), Religion Captain Bible in the dome of Darkness (BridgeStone Multimedia Group, 1994), Corporate Training and Advertising Pepsi Invaders (Atari, 1983).

The statistics show that maturity of releasing serious games $(65.8 \%, 953$ out of 1256 released) before 2002 is used for educational purpose, where after 2002 this number reduces to $25.7 \%$ and advertising take first place where share of it before 2002 was only $10.7 \%$. It indicates 
that serious games are used more in marketing and promotion of goods in the market [12].

They highlight the main reasons of delay of new labels for a serious game. Their reasoning indicates two main factors were obstacle to clarify this title: targeting entertainment as a main goal by game productions and violence of game contents which was the cause of the Columbine tragedy high school tragedy, that's why parents were sensitive about games.

The outcome of the analyses shows that success the serious games depended on industry success. It means the success of serious game that welcomed by the public, was that time that they were able to create a specific title for it and convincing families that content of serious games don't hurt children.

[13] Explains a platform named e- Adventure including a tool for generating prototype games and integrating with existing learning system named Learning Management System (LMS) and Learning Activity Management System (LAMS).

They address several barriers of existing approaches which used in both general-purpose and educationalpurpose game development, such cost, bottleneck, adopting video games in an educational environment, level of skills of educator in using tools, graphical issues in game development and so on.

From these challenges, they defend the method as Rapid Game Development that relies on eAdvanture framework.

The game architecture designed that the educator can generate a test version of the game and evaluating it before taking the full activity with students. Then a clear hand-drawn version will be scanned and then the game will be generated upon it. In this way they avoid barriers they mentioned in the philosophy of their attempt such cost, bottleneck.

\section{Prog\&Play a game-based tool to teach programming language}

Prog\&Play is another work on serious game, but in learning programming languages [11].

This serious game used to teach the fundamentals of programming, i.e. basic syntaxes and semantics of higher level languages, to undergraduate students. They based on Real-time strategy games and stated research questions:

1- What features of the game were stressed by teachers to explain Prog\&Play adoption or nonreuse?

2- What features of the teaching context promote learning with Prog\&Play?
They used an open source Real-Time, Kernel Panic is on strategy project on which based Prog\&Play. Kernel Panic has its graphic interface for setting the tanks, while Prog\&Play use any IDE in (C, Ada, Java, Compalgo, OCaml, and Scratch) to write little programs for setting up the tanks by the students.

In their literature review they explained that the serious games are widely used for: 1) motivation effects, 2) learning benefits, 3) entertainment potential. In this paper they investigate contextual effects that influence their two assumptions.

1) Video games are exciting for students.

2) Provide good context to embed computer programming, teaching materials.

The basic idea of Prog\&Play is to

1) Anchor learning with game

2) Provide teachers with a tool to choose

a) Teaching strategy and

b) Language and paradigm.

They tested on 260 students and 20 teachers in 7 different settings. They used questionnaires in each setting, for students and teachers. They analyzed their feedbacks, it suggest that Prog\&Play as a top tech requires "Prog\&Play is better suited to a project setting with time to discover the game and environment along with an adapted evaluation process including a reflection phase. Moreover, we think that Prog\&Play is better suited to imperative and object-oriented programming languages" [11].

\section{PRELIMINARY ANALYSIS}

If learning of one language has its difficulty. Learning of Kurdish language has some extra complications because of its nature. Language learning to compose of writing, speaking and comprehension. Kurdish language has some principle dialects and two different alphabets. So the basic decision is to decide the dialect and alphabets used in the learning process. In this project we work on the South Kirmanji dialect and Arami alphabets ${ }^{2}$.

Working on such a project requires a large amount of information. There is no existing data in this field in Kurdistan; it was hard for our group to step in this circumstance without any preliminary information. Because of couples of decisive questions arises in the beginning; no warranty what is the official alphabet of the languages? Does this alphabet will change? How users will interact with this new concept? Who will be the final real user? Why there is no any serious game to learn something in Kurdish? How we can control on the first

\footnotetext{
${ }^{2}$ http://www.kurdishacademy.org/?q=node/37
} 
step? How many children use electronic devices? How these devices used in school and home at free times?

\section{A. The survey}

The answer of all of these questions and so many others was not clear. We decided to make a survey and analyze results to have an idea about how we can begin and what we can do.

We have design designed three surveys (school administration, teachers and pupils) to define the range of gaming, using new technology, utilities etc. according to learning language. The first survey dedicated to primary students from $1^{\text {st }}$ to $6^{\text {th }}$ stages. We selected different gender from all stages. The survey consists of 11 questions. It targeted the pupil from age 6 to 12 years old. The main aim of our survey is to get understand the pupil feedback about the Kurdish serious game for learning. We visited different primary schools, public and private. We have completed 100 surveys. The administration of those schools gave us permission to carry out our survey in their school. They welcomed this project and supported us to fill this gap in developing serious games in education. In spite of the difference range of using technology among all pupils, but all have common using of them in their study or social life. They use computers, laptops, tablets, and smart phone to play different games.

\section{B. Results}

Question 4 in the survey was "do you play electronic games?" $78 \%$ answers yes and 22\% answered No. 53\% was male and $47 \%$ were female. It is clear that most of the pupils play electronic games. Types and percentages of playing games by pupils were video $28 \%$, Action Game $22 \%$, simple Game $28 \%$ and other games (non-Action games) as it is shown in (Fig. 4):

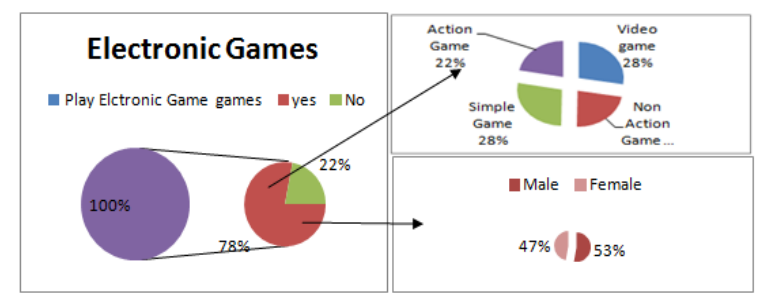

Fig. 3. The types of electronic games used by children

Question 5 in our survey was asked that "do you use electronic devices and which devices are used to play these games in the Home?" The result shows that $78 \%$ of pupils playing electronic games. Among them, 53\% using tablets at home, but only 5\% use it in school, $42 \%$ they don't have a tablet. $31 \%$ using mobile at home, $1 \%$ use mobile at school and $68 \%$ they don't use mobile. While there is a good similarity between using desktop and laptop computers, $45 \%$ using laptop at and $40 \%$ use desktop computers at home. Furthermore, $4 \%$ using laptop at school and 3\% use desktops. Although more than half of them, they don't use any kind of computer. It is obvious from these percentages that there is a common habit of using of devices for playing games among the pupils as it is shown in (Fig. 4). While in school it is forbidden to use most of these devices except computer labs, very few students will play games in school.

\section{Using of electronic devices}

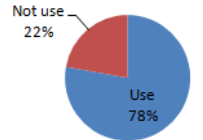

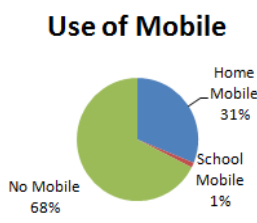

Use of Computer

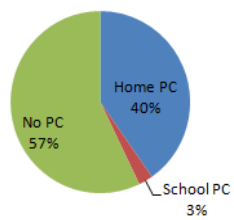

Use of Laptop

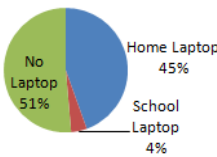

Use of Tablet
Fig. 4. Percentages by using electronic devices

Regarding to our project, Question 10 is another important question which was "what language you learn from using electronic games (Kurdish, English, Arabic and other?)". (Fig. 5) Shows that most of students will play games to learn English, Arabic and finally Kurdish language. The statistics demonstrate 74 pupils use games to learn writing, speaking and comprehension while this range in Kurdish language is 24 . Although they didn't know the name of the game played to learn Kurdish. The result shows that there must be more attention to serious game for learning Kurdish language because there are very few games regarding to this language which is the official language in the Kurdistan region. 


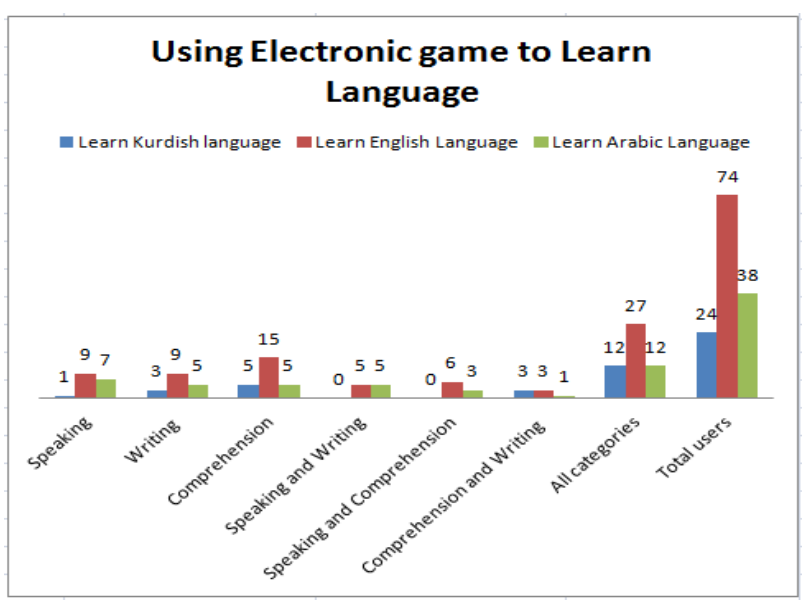

Fig. 5. Using electronic games to learn the language

Final Question we have asked pupils "which game you prefer to learn a language?" $37 \%$ of the pupils prefer using the computer game, though that $30 \%$ prefer using paper game in learning (Fig. 6). Therefore, this shows that the computer game is more preferable than all other games for learning languages. We have also collected a survey for school administration and teachers. All results of these surveys support our proposal regarding the importance of serious game for educational systems in general and especially for language learning. Consequently, the result approves our hypothesis that in Kurdistan there are strong needs to start and adopt serious game for learning language.

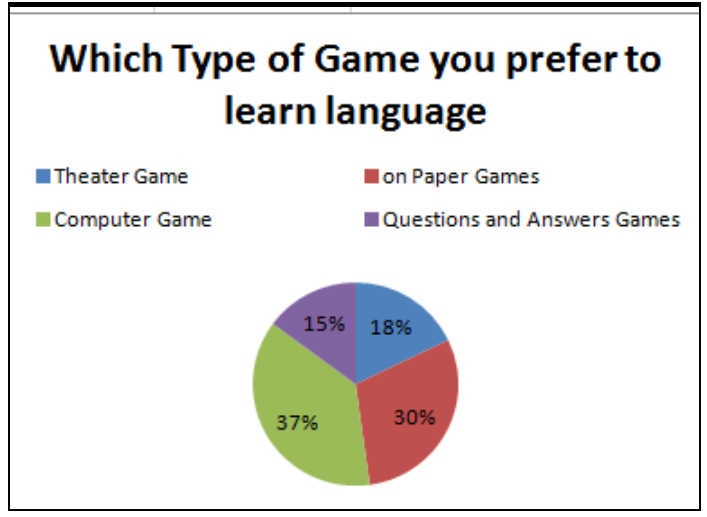

Fig. 6. Types of games played by children

\section{THE GAME}

\section{A. Design}

According our hypothesis and challenges in the study of Kurdish language, and testing the idea of learning a language by focusing writing approach, we designed a basic game that implemented in our prototype. The game includes different levels. In the first level, which designed for children who is not able to recognize letters, the game begins by falling a group of related objects and a sound plays asks to select target object i.e. which contains a specific letter. In the bottom of the console the player has to control the character which traverses horizontally to catch the correct object, then console updates and the game repeats to the end of the step designed by teacher (Fig. 7).

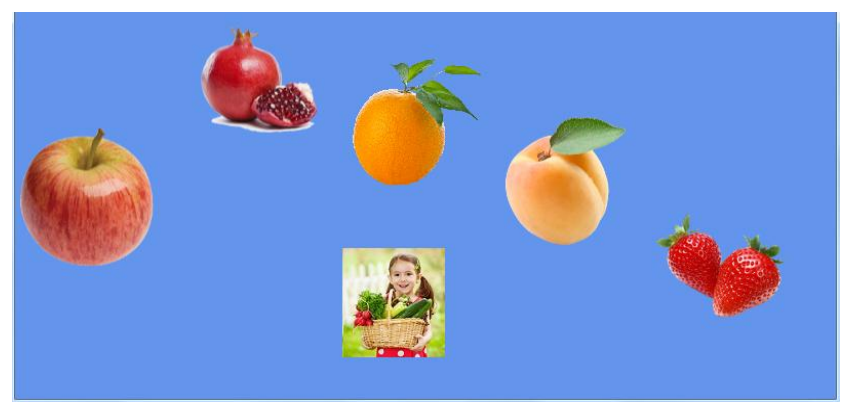

Fig. 7. Level1-Step1

At the second level the game begins by giving a picture and asking the player to select the correct word, which contains this letter. These levels are basic, level, that the answer is either correct or incorrect.

In the second level, the game displaying_an image and suggests a couple of almost identical words, that only one of the options is correct and the others are incorrect with different type of error (Table. 2). The player has to choose one of them.

Table 2: Answer details

\begin{tabular}{|c|c|c|c|}
\hline ID & Type of answers & Comment & Points \\
\hline 1 & Correct & $\begin{array}{c}\text { The word has no } \\
\text { other meaning }\end{array}$ & 10 \\
\hline 2 & One simple letter false & $\begin{array}{c}\text { The word has no } \\
\text { other meaning }\end{array}$ & 9 \\
\hline 3 & $\begin{array}{l}\text { One upper accentuated letter } \\
\text { false }\end{array}$ & $\begin{array}{c}\text { The word has no } \\
\text { other meaning }\end{array}$ & 8 \\
\hline 4 & $\begin{array}{l}\text { One lower accentuated letter } \\
\text { false }\end{array}$ & $\begin{array}{c}\text { The word has no } \\
\text { other meaning }\end{array}$ & 8 \\
\hline 5 & $\begin{array}{l}\text { Two upper accentuated letters } \\
\text { false }\end{array}$ & $\begin{array}{c}\text { The word has no } \\
\text { other meaning }\end{array}$ & 7 \\
\hline 6 & $\begin{array}{c}\text { Two lower accentuated letters } \\
\text { false }\end{array}$ & $\begin{array}{c}\text { The word has no } \\
\text { other meaning }\end{array}$ & 7 \\
\hline 7 & $\begin{array}{l}\text { Two mixed (upper and/or } \\
\text { lower) accentuated letters } \\
\text { false }\end{array}$ & $\begin{array}{c}\text { The word has no } \\
\text { other meaning }\end{array}$ & 7 \\
\hline 8 & $\begin{array}{c}\text { More than two upper } \\
\text { accentuated letters false }\end{array}$ & $\begin{array}{c}\text { The word has no } \\
\text { other meaning }\end{array}$ & 4 \\
\hline 9 & $\begin{array}{c}\text { More than two lower } \\
\text { accentuated letters false }\end{array}$ & $\begin{array}{c}\text { The word has no } \\
\text { other meaning }\end{array}$ & 4 \\
\hline 10 & $\begin{array}{c}\text { More than two mixed (upper } \\
\text { and/or lower) accentuated } \\
\text { letters false }\end{array}$ & $\begin{array}{c}\text { The word has no } \\
\text { other meaning }\end{array}$ & 4 \\
\hline 11 & Other & $\begin{array}{c}\text { The word has no } \\
\text { other meaning }\end{array}$ & 0 \\
\hline
\end{tabular}


The third level is designed to write object name by the player in Kurdish. This level requires that player must be able to write in Kurdish (Fig, 8).

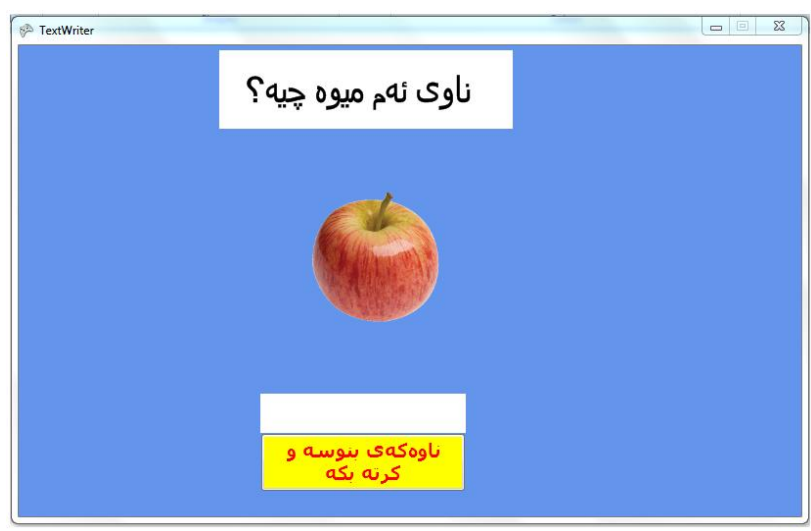

Fig. 8. Level3

In another level the game displays a couple of letters and player will be asked to create a meaningful word with them. If the answer is correct, then related picture will be displayed.

In advanced level words will be shown to the player then $\mathrm{s} / \mathrm{he}$ has to create sentences with them. This level focuses on Kurdish grammar and it will be used for higher student age.

Awarded points cumulated by the player can be used in next steps or levels to get more specific help and it is the one of the measures of the challenge between users if they want to share it between their groups.

Clone of the same type of question can be given to the same player if the same type of question didn't answer before and/or the player has not enough points to go to the next level.

From teacher's part, it is possible to customize the curriculum, i.e., s/he can define words, upload pictures and define answers with types and points awarded.

\section{B. Implementation}

The current prototype is implemented to the proof of our concept which we are trying to bring in the serious educational game. As mentioned in previous sections there are many methods have been experienced to learn a new language. Most of them focusing on comprehension techniques, or starting with complex rules of grammar language. We aim to test another approach which emphasizing on writing.

The prototype designed in .NET framework, including XNA as programming language and SQL server for storing data for later analysis. The final version will be used XML instead of SQL server for portability and adaptability for different OS/devices.
The prototype supports score-based approach. It means our goal in each step is the range of scores gained by players. To pass each step the user must score more than half of the expected sum of points. Earned points will be accumulated through all steps.

Points will be used to get help or hints when needed by the user. The challenge is here between players. The winner is who used less of its points to pass the questions.

Our plan for next versions is time consuming for the game. It means how much time is used by the user to pass a step and fulfill whole game. It's useful where the game takes place in the group and skilled students are not ranged only on scores, but they will be evaluated according to use time. It will make competition and encourage students to score better and develop their skills. So the problem becomes multi-criteria. And special techniques will be used on this face like the model of Markov [14].

\section{THE ALGORITHM}

This kind of project needs a dynamic algorithm to manage all different aspects of the game, compare players' answer with the database, gives the points, suggest new questions and providing suitable help in each step. In Jojo, we have a dynamic algorithm composed of a series of simplified algorithms. Each of them executes in a specific step, because in each level the type of answer will change. For example, in the first and second levels, the answers are multiple choices (pictures in level 1 and words in level 2). Player-Entery-Compare(playerInfo, playerAnswer) (Fig. 9) is a simple algorithm which compare students answer with the correct or suggests answers in the database.

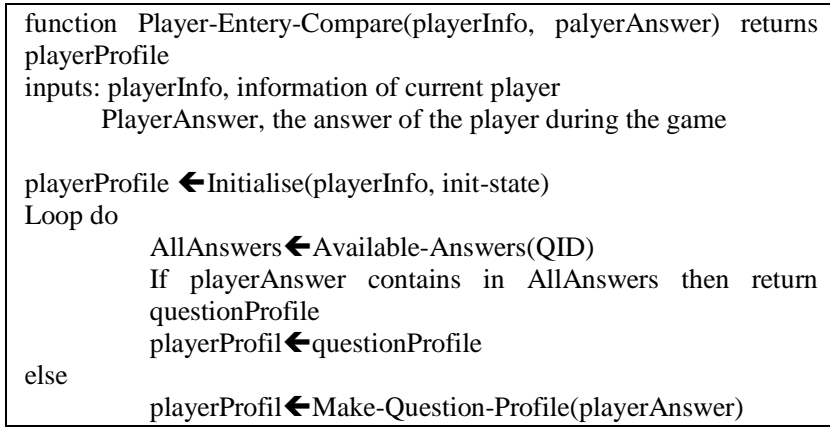

Fig. 9. Player-Entery-Compare function

At the beginning, the player can choose the type of his/her profile (anonymous or not). The algorithm takes this profile with the answer of current question and makes necessary modifications to the profile. Firstly, it initializes player's profile with available information entered by the player. Then make a loop to search in a database for all related information for the current question, for example, predefined answers, awarded points for each type of 
answer, type of question and its clone. After that compares the answer of the player with this list, if the player's answer is in the list all related information for this answer will be saved in his/her profile. If not, the players answer will be saved in the profile. The function Make-Question-Profile creates a profile for non predefined answers to be analyzed and integrated into the list in the future.

In level 1 and 2, selected answers are well formed because they are suggested by the system and the player just chooses one of them. But in the later levels player will write the answer so the analyses will be more complicated. Especially if the user uses one of the old versions of Kurdish keyboards like those used non Unicode fonts. Because these fonts does not easily supported by different systems. All player tracks will be saved in his/her profile. The current version uses traces only for providing help. The player can ask a help at any time on condition s/he has enough points. This is done via the Request-Help function (Fig. 10).

function Request-Help(playerProfile, playerBalance) returns help
inputs: playerBalance, the current balance of the player
playerProfile, the profile of the currrent player
Loop do
HelpWeight $\leftarrow$ Help-Weight(QID)
If playerBalance $\geq$ HelpWieght then return the help of
that question
counter++
playerProfile $\leftarrow$ Update-Asked-Help-Counter(counter)
else
$\quad \begin{aligned} & \text { if(Help-Counter>0) then return empty } \\ & \text { else } \\ & \text { return a simple hint } \\ & \text { counter++ }\end{aligned}$

Fig. 10. Request-Help function

If the player needs a help in the first level first step, the system gives a simple hint to show how to solve a problem. If the player asks again the system for the second time, the system does not respond. If the player asks a help after answering some questions correctly, the system compares his/her balance with the weight of the help demanded. If the player has enough points to get the help, the system gives the appropriate help.

Any time the player asks a help, the counter counts and puts it inside player's profile. The competition is based on several points, number of questions answered correctly, the number of help asked, time elapsed to answer each question, and type of errors in questions not answered correctly. Teachers in the class can use this competition to award points to those successfully win the game.

\section{CONCLUSION AND FUTURE WORK}

In this paper, we presented our hypothesis about learning a new language through serious games concentrating on writing approach. We studied related fields respected to theory of gaming and serious games, level of using technology and gaming with children in Kurdistan, policy and method of teaching language in the area. The purpose of this publication is to receive feedbacks from readers. Also, we want to position our work and register it as a first attempt in this field.

Our group selected Kurdish language / South Kirmanji and Arami alphabet as a target language and children from 4 to 12 years as a target user. We designed an algorithm and a game prototype to test our hypothesis. From our studies, including surveys and interview, it's obvious that there is a big demand to adopt technology and serious game in teaching approaches by authorities. Our survey was very helpful in designing this first prototype. We are aware of the difficulties of the project and found the way we can put through to achieve our goals.

We have plans to test our algorithm and prototype by real user, i.e. children and develop it to the final version that support different platforms including app stores. Likewise a web based version to collect data for test the robustness of our algorithms. We will develop a complete version, which will be a video game where a child go to turn on the fire of Newroz on a mountain and has difficulties in the way and wait him/her to solve these problems.

\section{ACKNOWLEDGMENT}

We thanks University of Human Development to support our group, and directors and teachers of all schools allowing us to perform our survey with their pupils.

\section{VIII.REFERENCES}

[1] M. Prensky, "True believers: Digital game-based learning in the military," Digital game-based learning, 2001.

[2] D. A. Norman, Things that make us smart: Defending human attributes in the age of the machine. Basic Books, 1993.

[3] M. Csikszentmihalyi, "Flow and the Psychology of Discovery and Invention," HarperPerennial, New York, 1997.

[4] H. Chen, R. T. Wigand, and M. S. Nilan, "Optimal experience of web activities," Computers in human behavior, vol. 15 , no. 5 , pp. 585-608, 1999.

[5] C. M. Finneran and P. Zhang, "A person-artefact-task (PAT) model of flow antecedents in computer-mediated environments," International Journal of Human-Computer Studies, vol. 59, no. 4, pp. 475-496, 2003.

[6] Y. X. Skadberg and J. R. Kimmel, "Visitors' flow experience while browsing a Web site: its measurement, contributing factors and consequences," Computers in human behavior, vol. 20, no. 3, pp. 403-422, 2004

[7] E. Sanchez, "When games meet learning," in IIGWE2011, 2011, pp. 9-13.

[8] M. R. Lepper, "Microcomputers in education: Motivational and social issues.," American Psychologist, vol. 40, no. 1, p. 1, 1985.

[9] R. Garris, R. Ahlers, and J. E. Driskell, "Games, motivation, and learning: A research and practice model," Simulation $1 \&$ gaming, vol. 33 , no. 4 , pp. 441-467, 2002. 
[10] B. H. Sørensen and B. Meyer, "Serious Games in language learning and teaching-a theoretical perspective," in Proceedings of the 3rd International Conference of the Digital Games Research Association, 2007, pp. 559-566.

[11] M. Muratet, E. Delozanne, P. Torguet, and F. Viallet, "Teachers concerns about context adaptation when using the Prog $\backslash \&$ Play Serious Game."

[12] D. Djaouti, J. Alvarez, J.-P. Jessel, and O. Rampnoux, "Origins of serious games," in Serious games and edutainment applications, Springer, 2011, pp. 25-43.

[13] Á. del Blanco, E. Marchiori, and B. Fernández-Manjón, "Adventure Games and Language Learning," Technological Innovation in the Teaching and Processing of Lsps: Proceedings of Tislid'10, p. 243, 2011.
[14] P. Perny, \& P. Weng. "On Finding Compromise Solutions in Multiobjective Markov Decision Processes”. In ECAI, pp. 969-970, August 2010

[15] D. Michael, \& S. Chen. "Serious Games: Games That Educate, Train, and Inform”. (1 er ed.). Course Technology PTR. 2005.

[16] J. Alvarez, V. Alvarez, D. Djaouti, \& L. Michaud. «Serious Games: Training \& Teaching - Healthcare - Defence \& security Information \& Communication". IDATE. 2010.

[17] T. Donovan. "Replay: The History of Video Games". Yellow Ant Media Ltd. 2010.

[18] M. Harfield. "Not Dark Yet: A Very Funny Book About a Very Serious Game". Loose Chippings Books. 2008 